\title{
PODERÁ A MODERNIDADE EDUCATIVA DIZER-SE SEM CÉLESTIN FREINET? O USO DA METÁFORA AGRÍCOLA PARA SE PENSAR EM EDUCAÇÃ ${ }^{1}$
}

\author{
¿SE PUEDE HABLAR LA MODERNIDAD EDUCATIVA SIN CELESTIN \\ FREINET? LA METÁFORA DE USO AGRÍCOLA PENSAR EN LA EDUCACIÓN
}

\author{
CAN EDUCATIVE MODERNITY BE SPOKEN OF WITHOUT CELESTIN \\ FREINET? THE USE OF THE AGRICULTURAL METAPHOR IN THINKING \\ ABOUT EDUCATION
}

RESUMO: Pretende-se compreender no estudo agora oferecido ao leitor o modo como a modernidade educativa, através da obra pedagógica de Célestin Freinet (1896-1966), se diz, ou não, pelo uso das metáforas, particularmente com o uso da metáfora agrícola. Neste contexto, o autor do artigo, predominantemente influenciado pelos estudos de Paul Ricoeur, Daniel Hameline e de Nanine Charbonnel sobre a metáfora tentará entender o modo como a metáfora agrícola se abre, ou não, ao símbolo e, em última instancia, questionar-se sobre a natureza desse mesmo símbolo que parte da metáfora para um nível semântico de natureza mais especulativa que propriamente educacional. Nesta linha de pensamento, a obra pedagógica de Célestin Freinet será analisada, a fim de melhor ilustrar não só o uso massivo da metáfora agrícola, mas também se pretende questionar o sentido hermenêutico educacional desse mesmo uso. Um questionamento que será já uma tentativa de resposta à pergunta inicial e que se pretende, desde logo, aberta e incitadora já de novas questões, mesmo que estas gerem um "conflito de interpretações" (Paul Ricoeur).

PALAVRAS-CHAVE: Modernidade educativa. Metáfora. Metáfora hortícola. Célestin Freinet.

RESUMEN: Su objetivo es comprender el estudio que ahora se ofrece al lector cómo la modernidad educativa a través de la labor pedagógica de Célestin Freinet (18961966), se dice, o no, por el uso de metáforas, en particular con el uso de la metáfora agrícola. En este contexto, el autor del artículo, predominantemente influenciada por los estudios de Paul Ricoeur, Daniel Hameline y Nanine Charbonnel en la metáfora tratar de comprender cómo se abre la metáfora agrícola o no el símbolo, y en última instancia, ser cuestionada sobre la naturaleza de ese símbolo de la metáfora a un nivel semántico de más especulativo que en realidad educativa. En línea con esto, la labor pedagógica de Célestin Freinet será analizada con el fin de ilustrar mejor no sólo el

\footnotetext{
${ }^{1}$ Esta publicação teve o apoio financeiro da FCT (Fundação para a Ciência e a Tecnologia - Lisboa Portugal) e do programa de financiamento POCH (Programa Operacional Capital Humano): financiamento comparticipado pelo Fundo Social Europeu e por fundos nacionais do MEC (Ministério da Educação e da Ciência - Lisboa - Portugal) (2015-2016)

${ }^{2}$ É Professor Catedrático do Departamento de Teoria da Educação e Educação Artística e Física do Instituto de Educação da Universidade do Minho (Braga-Portugal). E-mail: afaraujo@ie.uminho.pt
} 
uso masivo de la metáfora agrícola, pero también tiene la intención de cuestionar el sentido hermenéutico educativa de ese uso. Una cuestión que tendrá una respuesta a la pregunta original de la prueba y lo que se pretende, en primer lugar, abierto y incitadora tener nuevas preguntas, incluso si se traducen en "interpretaciones del conflicto" (Paul Ricoeur).

PALABRAS-CLAVE: Modernidad educativa. Metáfora. metáfora hortícola. Célestin Freinet.

ABSTRACT: In this study we shall try to understand the way educative modernity, through the pedagogical work of Célestin Freinet (1896-1966), can be expressed by the use of metaphors, in this case, the agricultural metaphor. In this context, the author, influenced mainly by the work of Paul Ricoeur, Daniel Hameline and Nanine Charbonnel on metaphor, will attempt to understand whether or not the agricultural metaphor is opened to symbol and to question the nature of the symbol itself, which starts in the metaphor and goes up to a semantical level which is more speculative in nature than properly educational. In this context, the pedagogical work of Freinet will be analyzed in order to illustrate in a better way not only the massive use of the agricultural metaphor but also to question the educational and hermeneutical meaning of that use itself. This questioning will be in itself part of the answer to the initial question and it also opens the way to other and new interrogations even if they generate themselves a "conflict of interpretations" (Paul Ricoeur).

KEYWORDS: Educative modernity. Metaphor. Horticultural metaphor. Célestin Freinet.

\section{Introduçãa ${ }^{3}$}

O desenvolvimento espiritual e a maturidade psicológica da criança tende a ser encarado pelos educadores e pedagogos da modernidade educativa, particularmente aqueles filados no movimento da Educação Nova, como Célestin Freinet (1896-1966) ${ }^{4}$, como se ela fosse uma planta com um ciclo natural de crescimento. Assim, o educador, à semelhança do jardineiro ${ }^{5}$, necessita de cuidar pacientemente ao longo do seu desenvolvimento integral (NÓVOA, 2005, p. 79; FREINET, 1994, T. 2, p. 107-108) ${ }^{6}$.

\footnotetext{
${ }^{3}$ Este texto é uma versão modificada em português de um texto escrito em língua inglesa para Sisyphus Journal of Education (Vol. 1, Issue 1, 2016).

${ }^{4}$ Consulte-se, J. Pain, « FREINET Célestin - (1896-1966) », Encyclopaedia Universalis [em linha] consultado em 9 dezembro 2015. URL : http://www.universalis.fr/encyclopedie/celestin-freinet/; H. Peyronie (1994). Célestin Freinet, In J. HOUSSAYE (Edit.). Quinze Pédagogues. Leur influence aujourd'hui, pp. 212-226.

${ }^{5}$ Veja-se "Le bon jardinier, ou le cycle de l'éducation" (1994, T. 2, p. 107-108).

${ }^{6}$ António Nóvoa salienta que o conceito de educação integral "é, provavelmente, aquele que melhor define a modernidade escolar e que se traduz pela necessidade de articular a educação física, intelectual e moral. Mais tarde, também se fala da necessidade do sujeito possuir uma consciência social integral (2005, p. 79).
} 
Tendo em conta o anteriormente dito, não de todo indiferente para estes autores "que o aluno seja comparado a um recipiente que se enche ou a uma planta que cresce" (HAMELINE, 1981, p. 121). De facto, não é, na verdade, de todo indiferente porquanto ambas as metáforas pedagógicas conduzem a conceções bem diferentes quer de aluno, quer de professor : a primeira, lembrando aqui Montaigne e Paulo Freire, aponta na direção das "cabeças cheias"7 e da "educação bancária"8 (Escola Tradicional no seu sentido mais geral), a segunda, também lembrando aqui os autores citados, aponta já na direção das "cabeças bem-feitas" e da "educação problematizadora" (Escola Nova). É por esta última conceção que a Educação Nova, como é bem conhecido, opta recorrendo a um conjunto de metáforas, particularmente a agrícola, para melhor legitimar os seus “ditos" educacionais, bem como para conferir-lhes uma respeitabilidade pelos quais eles anseiam. Quem diz respeitabilidade, diz eloquência pedagógica, diz também persuasão da retórica dos "ditos" pedagógico-educacionais onde a "similitude" nunca anda longe (HAMELINE, 1986, p. 125-127; CHARBONNEL, 1983, p. 157, 1994: 52).

À pergunta se a modernidade educativa poderá dizer-se sem Célestin Freinet e, por conseguinte, sem o uso da metáfora, nós, apoiando-nos na sua obra pedagógica, dividiremos o presente estudo em duas partes: na primeira trataremos da importância da metáfora agrícola na modernidade educativa, enquanto na segunda parte trataremos da metáfora agrícola na obra de Célestin Freinet. Defenderemos na nossa conclusão que dificilmente os tenores do movimento da Educação Nova (HAMELINE, 2000, p. 15-95) podem dispensar o lugar e a função da metáfora como, aliás, se viu no caso de Célestin Freinet.

\section{A adesão da modernidade educativa ao poder apelativo da metáfora agrícola}

A modernidade educativa não pode escapar ao poder e ao charme da metáfora, particularmente àquilo que Daniel Hameline designou por "a grande sonharia [songerie no original] hortícola" (1986, p. 182-185). A metáfora hortícola tem o dom heurístico

\footnotetext{
${ }^{7}$ Referimo-nos aqui à célebre passagem de Michel de Montaigne que nos seus Essais (1588), Livre I, Chap. XXV - De l'institution des enfants, salienta o seguinte: «gostaria que se tivesse o cuidado de escolher-lhe um preceptor que antes tivesse a cabeça bem-feita do que bem cheia, e que se lhe exigissem ambas as coisas, mais os costumes e o entendimento do que a ciência; e que em seu encargo ele se conduzisse de uma forma nova» (2005, p. 44).

${ }^{8}$ Consulte-se o Cap. 2. A concepção "bancária" da educação como instrumento da opressão. Seus pressupostos, sua crítica, p. 57-61 da obra de Paulo Freire intitulada Pedagogia do Oprimido (19681970). Veja-se o Cap. 2 - La Tête Bien Faite, p. 23-36 de Edgar Morin publicado na sua obra La Tête Bien Faite (1999).
} 
de transportar-nos, de fazer-nos percorrer, através de um desvio semântico (1981, p. 122), desde o sentido figurado, passando pelo questionamento do sentido da formação humana (Bildung, GENNARI, 2006, p. 4413-4418), até àquilo que Daniel Hameline designou de “crença 'fundamental', 'estruturante', 'originária': “se qualquer coisa é transportável de uma palavra a outra, se o aluno é, num sentido, uma planta que cresce, é que entre o aluno e a planta existe uma analogia que não é de modo algum da ordem da ornamentação do discurso, mas antes da ordem do ser" (1981, p. 123). Comparar a criança ao crescimento vegetal tal significava consagrar a ideia de "espontaneidade criadora da criança" (precisamente o tema do Congresso de Calais em 1921) como uma das ideias caras aos progressistas da Educação Nova.

\section{Para uma pequena caracterização da modernidade educativa}

Õ pedagogo francês, Célestin Freinet, inscreve-se na modernidade educativa tardia que, por sua vez, está marcada pela agenda pedagógica da "Liga internacional para a educação nova". Esta "Liga" tem por título, aliás não só sugestivo como profético, um órgão escrito de divulgação e informação intitulado Pour l'ère nouvelle. Neste órgão, além de outros temas, defendia-se instauração de um "tempo novo" e uma "nova era" de paz, onde o terror e o horror da guerra (falamos da I Guerra Mundial) nunca mais se repetisse: uma "era nova" povoada de "homens novos" formados pelos novos ideais caros à Educação Nova9 ${ }^{9}$. Os seus adeptos falam em rutura com o passado pedagógico (especialmente com as ideias da Escola Tradicional), mas trata-se antes de prolongar "uma corrente de ideias cuja presença é percetível ao longo do século XIX" (HAMELINE, 2000, p. 19). É portanto o século XIX, o século educador como lhe chama Daniel Hameline, que marca a modernidade educativa, iniciada no século XVIII pela filosofia das Luzes e que se prolonga até à contemporaneidade (2000, p. 22), constituída, segundo o autor, por três "lugares comuns": o do "progresso", o da “educabilidade" e o da "democracia igualitária" (2000, p. 25-36) ${ }^{10}$.

\footnotetext{
${ }^{9}$ Que tinha precisamente no ideal da paz um dos seus principais valores, como, aliás, o escreveu Maria Montessori na sua obra Educazione e pace de 1949.

${ }^{10}$ A este respeito, leia-se as palavras de Daniel Hameline sobre os significados destes "lugares comuns": "Trois lieux comuns me paraissent dominer l'idée que les sociétés modernes se font de l'éducation scolaire qu'elles entreprennent, peu à peu et irréversiblement d'organiser. Ces sociétés croient au progrès, à l'éducabilité humaine, à la supériorité de la démocratie égalitaire" (2000, p. 24).
} 
Todo este conjunto de "lugares comuns" (2000, p. 23-24) são visíveis na obra pedagógica de Célestin Freinet, ou seja, são passíveis de serem encontrados quer nas suas conceções e práticas pedagógicas, quer nas suas opções políticas. Sintomaticamente esses mesmos "lugares comuns" dificilmente escaparam ao charme da metáfora, veja-se, por exemplo, o uso da metáfora da luz para celebrar o "lugarcomum" de progresso: Post tenebras lux (HAMELINE, 2000, p. 25). Assim, não admira que a obra pedagógica do pedagogo francês não tenha escapado a esse mesmo charme, ou não tivesse colocado ela a educabilidade ${ }^{11}$ do educando sob o signo da metáfora agrícola por oposição às metáforas da modelagem, do recipiente e do enchimento.

\section{Da metáfora à metáfora em educação}

Lembrando a segunda parte da nossa epígrafe, que diz que "todo o dito sobre a educação situa-nos, ainda por muito tempo, nas margens incertas da Retórica, lá onde reina a metáfora, na ambiguidade das suas compulsões repetitivas e das suas impertinências criativas" (1986, p. 131), a nossa abordagem é fundamentalmente hermenêutica. A razão disso, é que não nos contentamos tão-somente com a instauração de uma nova pertinência semântica (domínio semântico), mas procuramos penetrar nos domínios do pensamento e do simbólico com todo o esforço hermenêutico que lhes assiste, tal como o estudou Jean-Jacques Wunenburger (2002, p. 91-103, 27-42) ${ }^{12}$. Neste contexto, encontramos a posição de Paul Ricoeur sobre a teoria da metáfora que acolhemos $(1976 \text {, p. 45-69, 1994) })^{13}$, embora sabendo que nem todas as metáforas

$11 \mathrm{O}$ credo humanista da educabilidade deve ler ler-se à luz do famoso adágio de Píndaro: "Torna-te naquilo que és".

12 Aqui somos devedores dos ensinamentos de Paul Ricœur que na sua The Rule of Metaphor escreve o seguinte: «The passage to the hermeneutic point of view corresponds to the change of level that moves from the sentence to discourse properly speaking (poem, narrative, essay, etc.) A new problematic emerges in connection with this point of view: the issue is no longer the form of metaphor [in case of the rhetoric] as a word-focused figure of speech, nor even just the sense of metaphor [in case of the semantic] as a founding of a new semantic pertinence, but the reference of the metaphorical statement as the power to 'redescribe' reality. The most fundamental support of this transition from semantics to hermeneutics is to be found in the connection in all discourse between sense, which it its internal organization, and reference, which is its power to refer to a reality outside of language. Accordingly, metaphor presents itself as a strategy of discourse that, while preserving and developing the creative power of language, preserves and develops the heuristic power wielded by fiction » (1994, p. 6 e 229-239).

13 Para o "estado da arte" sobre a metáfora, veja-se a obra editada por Jaakko Hintikka, Aspects of Metaphor (1994) Raymond Gibbs, Jr, intitulada The Cambridge handbook of metaphor and thought (2008) sobre a função e a natureza da metáfora nos mais diversos domínios científicos, nomeadamente no campo da educação. No mesmo sentido, consulte-se Metaphor and Thought edited by Andrew Ortony (1979) e na perspetiva filosófica da metáfora o livro editado por Mark Johnson intitulado Philosophical 
educacionais se equivalem e muito menos que possam reclamar-se de "vivas" no sentido que Paul Ricoeur lhe confere (1976, p. 52, 1994; HAMELINE, 1986, p. 79-82, 83-93). Deste modo, em síntese, a metáfora para o autor diz-se no entrelaçamento do sentido literal (denotação) com o figurativo (conotação); tem a ver com a semântica da frase; é um fenómeno de predicação e não de denominação; a metáfora é o resultado da tensão entre dois termos numa enunciação metafórica; uma metáfora de tensão não é traduzível porque criadora de sentido inovadora metáfora produz uma inovação semântica e por isso memso fornece uma nova informação acerca da realidade; finalmente uma metáfora não existe em si mesma, mas numa e por uma interpretação (RICOEUR, 1976, p. 46-53).

Assim, podemos, na linha de Daniel Hameline, dizer que uma das funções essenciais da metáfora é de "Fazer aparecer o pensamento" (1981, p. 130-131) ${ }^{14}$, quer dizer que esta deve atribuir uma figuração ao pensamento que se diz na linguagem. Como todos os "ditos" educativos se dizem na e pela linguagem e pretendem sempre pensar sobre a "coisa" educativa, logo as metáforas em educação são uma constante no pensamento educacional (SCHEFFLER, 2003, p. 73-88; HAMELINE, 1986; CHARBONNEL, 1991, 1991 a , 1993).

Mas de que metáfora estamos falando em educação? A resposta é que trata da metáfora in absentia ${ }^{15}$ que é aquela que, recorrendo à "similitude", melhor se encontra preparada para exprimir os "ditos" em educação, aquela que está melhor preparada para tornar a eloquência pedagógica, ou a eloquência dos "ditos" sobre a educação, um sucesso quer ao nível da "exposição declarativa de ideias de evidência convencional", quer de "incitação parenética aos sentimentos que não o são menos" (1986, p. 139). Por fim, embora Daniel Hameline saliente que o "é como..." analógico constitua uma "hermenêutica do pobre" (1986: 127) e que o "triunfo da similitude" seja modesto (1986, p. 135-139), o autor, em detrimento do símbolo e da sua hermenêutica que lhe é própria (1986, p. 129-135), acaba claramente por optar pela metáfora, ou seja, pelo

Perspectives on Metaphor (1981). No entanto, os trabalhos de Max Black estiveram igualmente no nosso horizonte de estudo da metáfora, particularmente a sua obra Models and metaphors. Studies in language and philosophy, assim como o clássico estudo de Georg Lakoff e de Mark Johnson sobre as Metaphors We Live by (1980).

${ }^{14}$ Neste contexto, nunca é demais realçar com Chaïm Perelman que "Aquilo que é certo é que o pensamento filosófico, não podendo ser verificado empiricamente, desenvolve-se numa argumentação que visa fazer admitir certas analogias e metáforas como elemento central de uma visão do mundo" (1988, p. 138).

15 Trata-se aqui da metáfora no sentido restrito: «Le caractère propre en est l'absence non seulement des outils de la comparaison (comme, tel, ainsi, tel que, pareil à, ressemble à, etc.), mais du comparé luimême ». [Example: « Ces touristes qui peuplent nos classes... »] (HAMELINE, 1986, p. 125). 
"triunfo da similitude". A razão disso, é porque, entre outos aspetos, particularmente a sua admiração pela retórica e argumentação (PERELMAN, 1988, 1989; PERELMAN; OLBRECHTS-TYTECA, 1992; REBOUL, 1994, HAMELINE，1986, p. 166-172), a "similitude" oferece ao discurso pedagógico, senão mesmo educacional, respeitabilidade, razoabilidade e legitimidade que é algo, aliás, que ele muito carece e porquê? Porquanto os "ditos" sobre educação pertencem predominantemente ao domínio do plausível ${ }^{16}$ e menos do verdadeiro e do cientificamente experimental, daí que necessite da metáfora, que aposta na similitude (HAMELINE, 1986, p. 126-127), para se dar a ver, a convencer, agir ou fazer agir e a comover ${ }^{17}$ :

Na realidade, no dito sobre a educação, o efeito da metáfora está ao serviço do projeto de fazer partilhar uma convicção, de incitar à ação, de legitimar uma prática ou de desqualificar uma outra. Ele é em si da ordem do pedagógico. O 'é como...' intervém para melhor fazer compreender, ao título da ilustração frequentemente pesada e conveniente. Conveniente na forma que ela adquire: os instrumentos da comparação são muito visíveis; conveniente pela pertinência perspicaz da imagerie [no original] conforme às expetativas (1986, p. 136).

As expetativas dos autores da Educação Nova passam por usarem a metáfora, nomeadamente a agrícola, para dizerem mais daquilo que o diriam quando falam do desenvolvimento e crescimento da criança na medida em que "A cultura da terra, matricial de muitos dos nossos pensamentos da cultura, é uma das grandes reservas em que se baseiam para compreender as coisas humanas" (HAMELINE, 1986, p. 184).

\section{Sob a influência da metáfora agrícola}

Os autores do movimento da Educação Nova, na sua grande maioria, utilizam a "metáfora hortícola" para melhor "celebrar o milagre da infância" (Daniel Hameline). O ideário da Educação Nova e os seus autores promovem um autêntico culto-ritual da planta (CHARBONNEL, 1989, p. 445-495). Este, por sua vez, manifesta-se através da

16 A metáfora procura, na economia da argumentação discursiva, produzir efeitos persuasivos, senão mesmo, no limite, abalar ou contribuir para o aprofundamento das convicções do interlocutor ou do leitor. A metáfora "donne lieu à une véritable invention rhétorique, cette recherche d'effets de conviction, de persuasion ou d'adhésion inscrit toujours la manifestation d'un thème métaphorique dans une péripétie argumentative où la métaphore se modalise in situ et fait cause commune et effet commun avec toute la figuration du discours » (HAMELINE; CHARBONNEL, 1982, p. 5).

${ }^{17}$ Daniel Hameline observa que não surpreende que no metafórico da educação seja 'c'est doceat qui l'emporte" (1986, p. 138). 
comparação agrícola, ou vegetal, com o conjunto de imagens naturalísticas que essa mesma comparação põe em movimento ou destila para melhor consagrar a excelência da infância:

A metáfora é assim subalterna na celebração do milagre da infância, desde logo que este se desenrola ao natural. Encarregam-na de 'dar a ver' o pequeno ser que se desenvolve por si próprio, segundo um plano que em si encerra e que não lhe poderia ser ditado do exterior, à semelhança da planta em torno da qual o bom jardineiro pedagogo se contenta de preparar e limpar o terreno (HAMELINE, 2000, p. 49).

Do exposto, percebe-se que a metáfora agrícola tenha exercido uma forte atração em vários autores do movimento da Educação Nova, Édouard Claparède (1873-1940) ${ }^{18}$, Adolphe Ferrière (1879-1960), Pierre Bovet (1878-1965), Célestin Freinet entre outros, utilizavam convictamente vocabulário próprio da horticultura para falarem do crescimento e desenvolvimento infantil (uma cultura da criança) em oposição às metáforas da modelagem, do mobiliar, do alimentar e do recipiente utilizadas pela Escola Tradicional (SNYDERS, 1975, p. 13-54), ainda que esta oposição deva ser atenuada (1986: 145-155) ${ }^{19}$ : “A metáfora hortícola é uma constante de todas as correntes pedagógicas que opuseram o lugar-comum do vivente a fazer (ou deixar) crescer, ao lugar-comum do produto (mecânico, mas mais frequentemente social) a modelar" (HAMELINE, 1986, p. 182).

Falar da figura do jardineiro e compará-la com as figuras do professor e do educador era uma constante muito apreciada pelos pedagogos partidários da Educação Nova: "a metáfora do jardineiro erigida em paradigma torna-se o instrumento que permite ver e compreender, numa primeira aproximação, que tem possibilidades, pela intuição do semelhante, de dizer de imediato o essencial" (1986, p. 180). Neste contexto, sublinhe-se que a metáfora agrícola correspondia bem à conceção que a Educação Nova possuía da criança e do modo como esta deveria ser educada. Esta analogia entre a pedagogia, como cientificamente conhecedora da criança, e a horticultura, como conhecedora (científica) das plantas, era aceite por parte dos "apóstolos" da Educação Nova como uma (quase) verdade elementar, tornou-se naquilo

${ }^{18}$ A este respeito, leia-se na sua obra intitulada Psychologie de l'Enfant et Pédagogie Expérimentale. I. Le développement mental a seguinte passagem: "Que la pédagogie doive reposer sur la connaissance de l'enfant comme l'horticulture repose sur la connaissance des plantes, c'est là une vérité qui semble élémentaire. Elle est pourtant entièrement méconnue de la plupart des pédagogues et de presque toutes les autorités scolaires » (CLAPAREDE, 1946, p. 71).

${ }^{19}$ Dizemos atenuada porque Daniel Hameline ressalta que a metáfora do "mobilar" o espírito parece não chocar o próprio Edouard Claparède (HAMELINE, 1986, p. 155). 
que Daniel Hameline designa de "lugar-comum" (1986, p. 61-72) das novas ideias educacionais: "A planta e a criança têm em comum serem ambos vivos e frutos de uma cultura: do mesmo modo que existe uma horticultura, pode-se falar de "puericultura" (1986, p. 181). Uma comparação, sofisticada, ou não, sob forma de similitude, (1986, p. 124-127), que rapidamente se exprime por um “dever ser” senão mesmo por aquilo que “deveria ser". Deste modo, passa-se da retórica para a ética, assim como se passa da retórica para a pedagogia e a filosofia da educação, quando se admite que as plantas e as crianças constituem um objeto de estudo sério porque científico, mesmo sabendo que: “a metáfora hortícola da educação só pode exprimir o romantismo da não-intervenção fazendo abstração, na imagerie [no original], da realidade da horticultura científica, brevemente industrial" (HAMELINE, 2000, p. 49).

Neste contexto, dificilmente podemos abordar os textos educacionais e pedagógicos do movimento da Educação Nova sem confrontarmo-nos com metáforas, desde as hortícolas (que subsumem o crescimento ou a cultura vegetal) até às da luz, passando pelas náuticas, pelas da viagem (que implica o percurso-deslocação), da modelagem, do enchimento-alimentação, entre outras ${ }^{20}$. Este conjunto de metáforas sempre foi, ainda que em grau diferente, utilizado mais ou menos voluntariamente, e no limite involuntariamente ${ }^{21}$, pelos pedagogos, psicólogos e educadores da Educação Nova para melhor darem a ver, para melhor ilustrarem, quase que sensitivamente, quase que oticamente, a educação e a relação pedagógica entre a criança e o educador. Particularmente, a metáfora agrícola, aliás muito presente nos textos consagrados às novas ideias educativas exprime sinteticamente a relação simbiótica e simbólica entre a educação da criança e o crescimento ou cultura vegetal. Este tipo de metáfora visa comparar, ainda que o grau comparativo varie na sua forma e na sua substância, o ciclo educacional-cultural da criança com o ciclo naturalista da planta que começa com o lançamento da semente, já numa terra previamente preparada, até ao gradual crescimento da planta que, à semelhança da criança, também ela um dia se tornará numa

20 Nanine Charbonnel chama a atenção para o seguinte leque de metáforas no discurso educativo: "Escultura e olaria, alimentação e enchimento, jardinagem, agricultura, domesticação, artesanatos diversos, marcha e navegação" (1983: 157). Sobre as metáforas do "enchimento", da "alimentação" e da modelação, consulte-se Nanine Charbonnel, 1991ª: 179-251 e 1993, p. 5-54. A este respeito, leia-se Israel Scheffler, 2003, p. 73-88.

${ }^{21}$ A este respeito, veja-se as palavras de Daniel Hameline: "mais le caractère propre de la métaphore, c'est que ceux qui en usent la veulent non métaphorique. C'est une vérité fondatrice que la comparaison a charge de professer" (1986, p. 182). O que significa portanto que muitos autores nem mesmo admitiam que nos seus escritos o jogo metafórico naturalista pudesse desempenhar um papel outro que o mero efeito estilístico ou retórico. 
flor ou mesmo numa árvore em toda a sua plenitude. Nesta linha percebe-se que a pedagogia faça da metáfora hortícola uma espécie de verdade elementar, algo que va de soi, ou seja, que se impõe naturalmente aos olhos daqueles que escrevem ou que falam sobre a coisa educativa: "Nós sabemos que a metáfora hortícola regressou, quase como uma obsessão, no início do século XX, junto daqueles que preconizam a educação nova" (HAMELINE, 2000, p. 49).

Não admira, assim, que Édouard Claparède, na sua obra intitulada Psychologie de l'enfant et pedagogie expérimentale (1905), tenha escrito que "é uma verdade que parece elementar" que a "pedagogia deva repousar sobre o conhecimento da criança como a horticultura repousa sobre o conhecimento das plantas" (1946, p. 71). Estas palavras sintetizam, a nosso ver, o postulado do "primado do biológico" que carateriza a "revolução coperniciana" que a Educação Nova representou no seio da tradição educativa ocidental ao fazer do adágio latino Discat a puero magister ${ }^{22}$ - que o mestre aprenda com o seu aluno - um dos seus principais leitmotiv. Os autores da Educação Nova usam a metáfora agrícola nos seus textos "como emblema da espontaneidade" para melhor insistirem que se deve respeitar o crescimento natural da criança tal como o jardineiro o faz relativamente às plantas que ele cuida (HAMELINE, 1986, p. 183).

Os textos que falam da educação dificilmente se podem furtar aos olhares atentos da metáfora e do símbolo porque aquilo que de mais dramático pode acontecer, segundo Olivier Reboul, é assistir-se a "uma educação sem símbolos face a símbolos sem educação" (1992, p. 217-219). É precisamente para contrariar a possibilidade de uma educação sem símbolos e metáforas ou, no limite, uma educação habitada por símbolos e metáforas mortas que escolhemos o exemplo da metáfora agrícola para ilustrar que a modernidade educativa, especialmente o movimento da Educação Nova exemplificado

\footnotetext{
${ }^{22}$ É este adágio latino que serve de emblema ao Instituto Jean-Jacques Rousseau fundado por Édouard Claparède em Genève, 1912: “A divisa do nosso Instituto - Discat a puero magister - indica por si o espírito: nós desejáramos colocar o mais possível os futuros educadores em contacto com a criança para que eles aprendam a conhecê-la e a amá-la. E o espírito que a inspira é o espírito científico, quer dizer a ausência de preconceito, o cuidado de 'tudo examinar para reter aquilo que é bom', segundo o liberal preceito do apóstolo. Em pedagogia como em ciência, é a experiência que julga fundamento das teorias e dos métodos" (CLAPARĖDE, 1946, p. 50-51).

Daniel Hameline quando se refere a uma das características chave da Educação Nova diz que « le rôle de la psychologie de l'enfant est d'effectuer la 'révolution copernicienne' qui fera tourner les programmes autour de l'enfant et non l'enfant se perdre dans les circonvolutions des programmes. Le postulat de cette révolution n'est autre que la primauté du biologique [itálico do autor]» (1986, p. 182). Sobre o movimento da Educação Nova consulte-se, entre muitos outros, os seguintes autores: BLOCH, 1973; HAMELINE; HELMCHEN; OELKERS, 1995; MÉDICI, 1995, p. 9-40; NÓVOA, 1995, p. 25-41, 1997, p. 71-96; SYNYDERS, 1975, p. 55-130 e VASCONCELOS, 1915.
} 
pela obra pedagógica de Célestin Freinet $^{23}$, não se pode pensar nem escrever sem o recurso semântico (CHARBONNEL, 1991 a, p. 111-115) e mesmo hermenêutico (RICOEUR, 1975, 1976, p. 46-53) da metáfora agrícola.

\section{A importância da metáfora agrícola na obra pedagógica de Célestin Freinet}

Célestin Freinet serve-se abundantemente da metáfora hortícola na sua obra pedagógica para melhor ilustrar as suas ideias pedagógicas e cientificizantes sobre a educação. No quadro da sua obra pedagógica estamos a pensar concretamente na The Wisdom of Matthew (1949) e no seu Essay on Psychology Sensitive (1950 - Essai de psychologie sensible). Deste modo, não é estranho que as imagens agrícolas e naturalistas usadas por Célestin Freinet sirvam, em nome do "triunfo da similitude" (HAMELINE, 1986, p. 135-139), para melhor ilustrar e consagrar o substrato filosófico-educacional do seu pensamento contaminado pelo naturalismo e pelos princípios da higiene natural, além da crença nas virtudes de uma natureza, muitas vezes equívoca (humana ou a natureza em si), acolhedora e regeneradora do próprio homem (PIATON, 1974, p. 202). Por fim, importa sublinhar que a metáfora agrícola é uma das metáforas fundadoras que sobredetermina a obra do nosso autor e que consiste precisamente na comparação da criança com o crescimento vegetal (CHARBONNEL, 1994, p. 51-59).

A criança, à semelhança da planta, é uma natureza em liberdade que a metáfora agrícola procura traduzir na sua máxima expressividade. Este tipo de metáfora destinase, nas mãos de Célestin Freinet, a melhor fazer compreender a evolução e a formação da criança, além de pretender mostrar que ela possui a "mesma natureza que o adulto". A criança aparece então como uma "árvore que ainda não acabou o seu crescimento, mas que se alimenta, cresce e se defende exatamente como a árvore adulta" (1994 (T. 2), p. 387). Em síntese, o autor, na linha da grande maioria dos atores do movimento da Educação Nova, utiliza a "metáfora hortícola" para, na feliz expressão de Daniel Hameline, melhor “celebrar o milagre da infância” (2000, p. 49).

\section{O significado da metáfora agrícola nos seus textos pedagógicos de Freinet}

${ }^{23}$ Sobre a obra pedagógica de Célestin Freinet, veja-se, na Bibliografia, as obras citadas na secção "Bsobre o seu pensamento". 
Os enunciados metafóricos, por nós selecionados na obra pedagógica de Célestin Freinet (1994 (T 1 e T 2), inscrevem-se naquilo que Nanine Charbonnel designou de regimes semânticos praxeológico (praxéologique) ou praxeo-prescritivo (1983, p. 158; $1991^{\text {a }}$, p. 82-88, 164-177, 1994, p. 54, 1999, p. 35) e cognitivo (1994, p. 56). A gramática destes regimes, muito brevemente, pode assim ser descrita: o regime semântico cognitivo exprime conhecimento da realidade, compreender o ser: "Quando Niels Bohr dizia do núcleo do átomo, em volta do qual giravam os eletrões 'é o sol dos eletrões' [e isso é verdadeiro, - ou falso" (1999, p. 34-35). Quanto ao regime semântico praxeológico ou praxeo-prescritivo, que é aquele regime que ordena expressamente, prescreve, impõe qualquer coisa a respeito de uma praxis, os seus enunciados "não se contentam de veicular um ato de linguagem de expressividade. Eles fazem outra coisa: pelo apelo a um comparante (sempre heterogéneo) e valorizado (como no regime semântico expressivo) eles ordenam ao leitor, ao interlocutor, qualquer coisa que devem fazer, na praxis extralinguística. Dizer: 'A criança é uma planta que tem necessidade de muito sol' (Michelet) é ordenar expressamente ao pai de dar afeto à criança" (1999, p. 35). Uma das caraterísticas maiores deste regime é que "Aquilo que carateriza o comparante no regime semântico praxeológico, é que ele é encarado não somente como semelhante, mas como imitável" (1999, p. 54 - o itálico é da própria autora). Nanine Charbonnel salienta que o mecanismo do enunciado metafórico é o mesmo em ambos os casos e que se encontra na base de todo o enunciado metafórico: ele consiste em identificar (ou a relacionar, aproximar) duas entidades que não são do mesmo género provocando, por conseguinte, uma dissimetria porque ao comparar-se duas entidades que não são do mesmo género está-se a fazer da "entidade comparante o portador por excelência de um traço semântico não ontologicamente constituinte" (1999, p. 34).

Quando Nanine Charbonnel afirma que toda a obra escrita de Freinet não possui outro objetivo que não seja o de "induzir à ação, que aconselhar à boa ação" (1994, p. 51) pensamos que, excetuando especialmente o seu Essay on Psychology Sensitive, a autora é justa na sua afirmação. A razão do nosso acordo deve-se ao facto de Célestin Freinet servir-se muito especialmente da metáfora agrícola para veicular injunções de tipo praxeológico (CHARBONNEL, 1991ª, p. 164-177, 1994, p. 52-55). Este tipo de 
injunções apelam a que se aja bem, ou seja, à prática da "boa ação" 24 e a agir na direção certa sob a forma do conselho:

nós somos desde o princípio [refere-se à obra The Wisdom of Matthew] inseridos no universo do conselho e da deontologia (para não empregar as palavras de moral, imediatamente entendidas como moralismo, nem de ética que, aliás, não convêm aqui). Não: convêm melhor as noções de conselho (retomando de Erasmo o seu personagem de Boulè-Phore: Senhor que Transporta-Conselho, Senhor Conselheiro, eu chamo o boulefórico [boulèphorique]) e de deontologia: aquilo que eu devo fazer profissionalmente. É exatamente nisto que se trata neste livro (1994, p. $54,1991^{\text {a }}$, p. $82-88$, 1999, p. 35).

Em síntese, os enunciados metafóricos usados, voluntariamente ou involuntariamente, por Célestin Freinet na sua obra pedagógica, particularmente na The Wisdom of Matthew, incitam à “injunção pela ação" $\left(1994\right.$, p. 55) ${ }^{25}$. É neste sentido que apontam as duas primeiras citações que adiante faremos e que foram extraídas The Wisdom of Matthew, enquanto as duas últimas foram por nós recolhidas no Essay of Psychology Sensitive e já tendem a inscrever-se no regime cognitivo, ainda que Nanine Charbonnel, neste caso concreto, prefira antes falar de "pseudo-cognição" (1994, p. 5559).

O pedagogo, à semelhança do "bom jardineiro" que cuida zelosamente das suas plantas, deve agir como ele no tocante às crianças que tem a seu cargo. Assim como o "bom jardineiro" cuida das suas plantas, para que elas possam florir e dar os seus frutos, o educador deve igualmente aguardar pacientemente que a criança, à semelhança da planta, se desenvolva, cresça e amadureça no meio que aquele previamente lhe criou. $\mathrm{O}$ educador, à semelhança do jardineiro que deve possuir o necessário savoir-faire para escolher as boas sementes e prepará-las para que elas deem, futuramente, bons frutos, também o educador tem que lidar com a infância como se esta fosse uma semente delicada e, por isso, ajudá-la a construir por si mesma a sua personalidade nas melhores condições possíveis que passam necessariamente por um "meio", um "material" e uma

${ }^{24}$ Como exemplo de metáforas hortícolas que se inscrevem neste regime, presentes em The Wisdom of Matthew, basta referir os seguintes ditos: "La vie monte toujours!" (Freinet, 1994 (T. 2), p. 112), "Donner soif à l'enfant" (1994 (T. 2), p. 114-115) e "Aller en Profondeur" (1994 (T. 2), p. 188).

${ }^{25}$ Em The Wisdom of Matthew, onde se lê Aller en Profondeur (FREINET, 1994 (T. 2), p. 188), percebese, desde o início, que estamos mergulhados no universo do conselho e da deontologia, além das observações experimentadas: "Et de l'observation expérimentée naît l'injonction, le bon conseil" (1994, p. 54). Aquilo que acentua o efeito do boulefórico e da injunção é a similitude que torna os "ditos" convincentes em que os vários tipos de frutos, de plantas, de flores são tantas vezes descritos antropomorficamente. 
"técnica" suscetíveis de ajudar a sua formação de acordo com as suas aptidões, gostos e necessidades (FREINET, 1994 (T. 2), p. 108). O pedagogo deve estar atento para que a criança tenha condições saudáveis para que ela se possa desenvolver tonificada à semelhança do fruto que tem uma boa terra adubada para melhor se fortalecer: "O fruto [leia-se também criança] é o resultado da terra [leia-se também sociedade-escola] onde ele radica, além da raiz, do ar e da folha" (1994 (T. 2), p. 108). O pedagogo ou o educador deve preocupar-se com as boas condições de vida do educando (FREINET, 1994 (T. 1), p. 333-339), do mesmo modo que o jardineiro se preocupa com a terra que acolheu a semente:

$\mathrm{O}$ aprendiz do jardineiro orgulhava-se dos seus melões que cresciam vigorosos e luxuriantes, em cavidades pouco profundas e dispostos em linha regulares que ele alimentaria copiosamente de água e de estrume. (...) Quantos pais, quantos pedagogos praticam como o aprendiz de jardineiro! E acumulam ao alcance da criança a alimentação prestes a ser ingerida: manuais abundantes e ricos, explicações e lições concentradas, deveres cuidadosamente racionalizados para evitar aos jovens rebentos todos os esforços inúteis (FREINET, 1994 (T. 2), p. 188).

Do mesmo modo que a planta gosta e aprecia ser cuidada pelo jardineiro, também o educando aprecia ser guiado, motivado e aconselhado em vez de ser obrigado autoritariamente a executar determinada tarefa sem que compreenda a necessidade, ou mesmo a sua razão de ser (FREINET, 1994 (T. 2), p. 391-392). Assim como o jardineiro que não pode nem deve usar "gestos bruscos que despertem as reações de defesa" das suas plantas, o mesmo é solicitado ao educador e ao pedagogo que imitem esse gesto sábio do jardineiro ou horticultor, pois o que a criança precisa, assim como a planta, é de "confiança, bondade, ajuda e decisão" por parte daqueles (as) que dela se ocupam (1994 (T. 2), p. 105). Todos (as) aqueles (as) que das crianças se ocupam devem preocupar-se com que o educando, para amadurecer, absorva paulatinamente os conhecimentos da "escola da vida" (1994 (T. 2), p. 108) ${ }^{26}$ à semelhança do jardineiro que se preocupa que a semente absorva o mais lentamente possível o húmus da terra para fortalecer-se e crescer: "Deixai a criança tatear, esticar os seus tentáculos, experimentar e cavar, investigar e comparar, manusear livros e fichas, mergulhar a sua curiosidade nas profundezas caprichosas do conhecimento, na busca, por vezes árdua, da comida que lhe é substancial" (1994 (T. 2), p. 188). A criança é como uma "pequena

${ }^{26}$ Esta é sinónimo da "escola do trabalho" enquanto "escola do futuro". 
planta”, ambas fazem parte da vida, e esta, como diz Mathieu, só se prepara pela vida ${ }^{27}$. A proposta pedagógica de Célestin Freinet baseia-se em leis que se reclamam da tradição da psicologia vitalista (BOUMARD, 1996, p. 47-51; PIATON, 1974, p. 173198): dizendo a primeira que "a vida é” (FREINET, 1994 (T. 1): 335-336), e a segunda que fala do "sentido dinâmico da vida" (1994 (T. 1), p. 339)²8: “A educação não é uma fórmula de escola, mas uma obra de vida" (1994 (T2), p. 107).

A escola não deve ser, portanto, aquele jardim abandonado que "não prepara mais para a vida", mas sim um jardim onde o jato de água fresca borbulha entre as pedras (1994 (T. 2), p. 115). Por outras palavras, a "escola tradicional”, ao ser responsável por uma instrução passiva e formal, faz dos alunos "odres bem cheios", impedindo-os assim de contactarem com as fontes da vida (o meio natural e o meio familiar) (1994 (T. 2), p. 396-397), como também os impede de terem “cabeças bem-feitas e mãos destras”. Ou seja, a "escola tradicional", com os seus métodos verbalistas que estiolam o apetite intelectual das crianças, não ajuda nem as crianças a construírem a sua personalidade, nem a desenvolverem e a estimularem as suas faculdades criativas e ativas. Neste sentido, é que os "bons educadores" não devem seguir os "escolásticos" que se deixam "hipnotizar por esses lagos caprichosos da observação, da memória, das teorias formais amontoadas na terra desolada da velha escolástica" (1994 (T. 2), p. 115), e que fazem da trilogia "estudar, copiar, repetir" (1994 (T. 2), p. 123) a sua varinha mágica. Por isso mesmo, é que Célestin Freinet propõe que o "bom educador" oponha à "blasfema pedagógica", que é o "escolasticismo" (1994 (T. 2), p. 177-78), um novo ciclo educativo ilustrado pela "escola do trabalho" como "escola do futuro" (1994 (T. 2), p. 19, 173-174, 1994 (T. 1), p. 157):

Se os homens soubessem um dia cuidar da formação das suas crianças como o bom jardineiro pela riqueza do seu jardim, eles cessariam de seguir os escolásticos que produzem nas suas cavernas frutos envenenados que conduzem à morte tanto aqueles que os produziram, como aqueles que foram obrigados a comê-los. Eles ["os bons educadores"] restabeleceriam corajosamente o ciclo verdadeiro da

${ }^{27} \mathrm{O}$ tema da vida é recorrente não obra educacional e pedagógica de Célestin Freinet, a título de exemplo: «L'éducation n'est pas une formule d'école, mais une œuvre de vie » (1994 (T. 2), p. 107) e «La vie se prépare par la vie » (1994 (T. 2), p. 119).

${ }^{28}$ É esta consagração à vida, por parte de Célestin Freinet, que nos autoriza a dizer, na companhia de Georges Piaton, que a sua filosofia está impregnada de naturalismo e de naturismo (1974, p. 201-205). O naturalismo do pedagogo concebe a natureza como criadora e reparadora, tendo esta a função de servir de modelo para o crescimento e formação das crianças. $\mathrm{O}$ autor procurava, através de uma higiene natural e de um ambiente natural, proporcionar aos educandos um equilíbrio simultaneamente fisiológico e psicológico. 
educação que é: a escolha da semente, o cuidado particular na escolha do meio no qual o indivíduo prolongará, para sempre, as suas poderosas raízes, a assimilação pelo arbusto da riqueza deste meio. A cultura humana seria, então, a flor esplêndida, uma promessa segura do fruto generoso que amanhã amadurecerá. (FREINET, 1994 (T. 2), p. 108).

Uma escola deste tipo deverá eleger como sua principal orientação pedagógica aquilo que Célestin Freinet designou de, pedagogia do "bom senso" (1994 (T. 2), p. 105), em ordem a formar um sujeito "suficientemente forte e harmoniosamente constituído" à semelhança de uma árvore que "soube responder aos efeitos do obstáculo segundo as suas possibilidades funcionais" (1994 (T. 1), p. 387). O ciclo "verdadeiro da educação" insiste Célestin Freinet deve seguir o exemplo do ciclo da natureza vegetal para que a criança se desenvolva de acordo com as leis específicas da sua formação. Daí não hesitar em compará-la a um grão de trigo:

A criança nasce e cresce como o grão de trigo. Se o meio onde ela se encontra assegura os princípios essenciais à sua alimentação, nem muito diluídos, nem muito concentrados, numa atmosfera favorável, iluminada de viva luz e de afeção atenta, o jovem ser cresce também com a máxima vitalidade de que ele é capaz. Ele cumpre então o seu destino do momento que é de aumentar as suas células na harmonia orgânica e de abrir à vida. Mas se as suas necessidades orgânicas não são satisfeitas como o exige a sua natureza, o indivíduo inquieto e perturbado procura obstinadamente o meio de remediar às suas deficiências que lhe provocam um obscuro sofrimento. O seu corpo estiola-se, a sua inteligência retrai-se, mas até ao último sopro de vida persistirá este incessante esforço que o levará a realizar a ordem não formulada mas impetuosa do seu destino. Se o solo é muito duro e muito magro, o rebento do trigo alongará desmedidamente as suas raízes; ele enterrá-las-á obstinadamente, à procura de água e de matérias fertilizantes; ele tateará, lutará, ensaiará ainda voltar atrás para sempre repartir, porque é para ele uma questão de vida ou de morte, e que pertence igualmente à sua essência crescer, prosperar para frutificar (FREINET, 1994 (T. 1), p. 334-335).

Na base desta citação emblemática, que se encontra no Essay of Psychology Sensitive, gostaríamos de sublinhar que o emprego da metáfora agrícola, por parte de Célestin Freinet, parece remeter para a sua conceção de psicologia humana como, aliás, o observa Nanine Charbonnel: "Ora, não se trata somente de Freinet edificar uma psicologia humana sobre a imagem de uma psicologia vegetal, mas ainda, na realidade, a sua fisiologia vegetal não é outra coisa do que uma psicologia humana disfarçada" (1994, p. 59). Uma psicologia humana, intimamente ligada a uma filosofia geral da vida 
que, para melhor falar dela e do modelo de homem que a enforma, não hesita em recorrer a exemplos retirados da vida vegetal; o segundo aspeto já não se trata de comparar, pelo mecanismo da similitudo, o pedagogo ao "bom jardineiro", mas usa-se a comparatio para convencer que a criança e o organismo humano, assim como o grão de trigo e a árvore pertencem ao mundo da natureza. Trata-se de algo sério porque procura estabelecer uma psicologia (que tem a ver com as leis do comportamento) que visa lançar as bases científicas de uma pedagogia inovadora:

Haverá uma diferença com os ditos de Mateus? Sim, e massiva: não existe mais o jardineiro! É que nós estamos num Ensaio de Psicologia: trata-se de coisas sérias. Não se trata mais de pregar a pedagogia, mas de fundá-la; logo não se trata de propor à imitação dos seres humanos (o bom pastor, o bom jardineiro), mas de atualizar as leis da natureza (CHARBONNEL, 1994, p. 59).

Mas por detrás deste esforço cognitivo (mesmo cientificizante), visível na sua Psychology sensitive, Nanine Charbonnel afirma que Célestin Freinet procura fundar uma psicologia humana na base de uma fisiologia vegetal, "mas também, na realidade, a sua fisiologia vegetal não é outra coisa, ela, que uma psicologia humana disfarçada" (1994, p. 59). Arriscamos mesmo dizer que por detrás mesmo deste esforço, Célestin Freinet esconde uma vontade de persuadir o leitor da justeza da sua conceção psicológica. A este respeito, não é talvez despiciendo observar que dado enunciado metafórico, inscrito no regime semântico cognitivo ou pseudo-cognitivo, que é suposto conhecer determinada realidade, compreender mesmo a sua razão de ser possa ocultar um sentimento (próprio do regime semântico expressivo) ${ }^{29}$ ou um juízo de valor ou uma prescrição (próprio do regime semântico praxeo-prescritivo), deixando muitas vezes o leitor confuso e tocado na sua afetividade (pathos): "Tudo ver sob a ótica da qualidade afetiva, mas tudo encobrir sob um apelo à Natureza, aos animais ou aos objetos, tal é talvez o genial e terrível contributo do "raciocínio metafórico"” (CHARBONNEL, 1983, p. 158).

Decorrente do exposto, pensamos que a par da metáfora agrícola, que é sempre uma metáfora do crescimento, patente nos textos de Célestin Freinet se pode igualmente realçar o lugar que a metáfora orgânica (SCHEFFLER, 2003, p. 80-88), intimamente ligada à metáfora agrícola, ocupa na sua obra, particularmente na sua Essay of

${ }^{29} \mathrm{O}$ regime semântico expressivo exprime um dado sentimento e atribui também um valor a uma situação determinada: "Quand Roméo dit de Juliette 'c'est le soleil de mes journées' » (CHARBONNEL, 1999, p. $34-35)$. 
Psychology sensitive. O autor mesmo nesta obra, que pretende que seja o seu contributo científico, a partir da psicologia, no campo educacional não deixa de comparar o indivíduo a uma árvore. Aliás, como ele escreve:

Nós comparamos o organismo humano à árvore que sai da terra, mais ou menos vigorosa porque mais ou menos bem enraizada $\mathrm{e}$ alimentada, e que crescerá tanto melhor se ela provém de uma boa semente, e que ela se encontre num solo que lhe convém porque ele a alimenta da sua seiva específica. Se ela emerge da terra nas melhores condições, ela organiza normalmente a sua vida segundo as leis da sua espécie. Se a luz lhe chega igualmente de todos os lados, se nenhuma árvore vizinha a incomoda com o seu contacto ou com a sua sombra, se nenhum muro impede a sua expansão, se nenhum acidente a mutila, ela cresce naturalmente, em largura e em altura, em equilíbrio sobre o seu tronco que vai endurecendo e ganhando espessura à medida que vai crescendo. Vocês veem então que respira a vitalidade e a harmonia (1994 (T. 1), p. 416-417).

Assim, parece reclamar o mesmo estatuto orgânico quer para o indivíduo, quer para a planta. O que parece significar que a cultura vegetal e a formação psicológica e antropológica do sujeito se não se equivalem, pelo menos andam próximas. Por outras palavras o crescimento da planta é análogo à vida e crescimento de um organismo individual. Deste modo, a cumplicidade orgânica estabelecida entre o organismo humano e a planta (a árvore por exemplo) parece ser evidente, visto que a continuidade da vida da planta e do organismo humano se assemelham: "A metáfora orgânica [...] conduz a comparar os processos de aculturação aos processos de regeneração nos organismos biológicos" (SCHEFFLER, 2003, p. 8).

\section{Da metáfora agrícola ao simbolismo vegetal}

Se o contributo de Nanine Charbonnel se revela original no tocante à análise da metáfora agrícola na base dos seus "regimes semânticos" (1991ª, p. 128-177; 1999, p. 34-35) sob o signo do "ver como" da similitude (CHARBONNEL, 1993 (T. 3), p. 99106) e do "é como..." da similitude (HAMELINE, 1986, p. 135-139) ${ }^{30}$ (domínio semântico por excelência), a nossa intenção é, contudo, adotarmos, na linha da teoria da

${ }^{30}$ A metáfora agrícola aparece do lado da similitude, porquanto compara entidades heterogéneas e pertencentes a géneros ontológicos diferentes, como é exemplo a comparação que Célestin Freinet faz entre a criança e um grão de trigo (1994 (T. 1), p. 334). A metáfora hortícola, tal como a entende Daniel Hameline, serve de um meio pertinente para exprimir a analogia, a similitude entre o crescimento natural da planta e o crescimento da criança, entre « les éléments du comparé (l'enseignement) et du comparant (le nourrissage de la plante) » (CHARBONNEL, 1994, p. 54-55). Refira-se que se está a falar de géneros ontológicos diferentes como se compreende. 
metáfora viva de Paul Ricoeur, uma perspetiva decisivamente hermenêutica como já o dissemos na primeira parte do nosso trabalho ${ }^{31}$. O porquê desta opção reside na convicção que esta abordagem permitir-nos-á interpretar a metáfora agrícola de um modo mais radical, como aliás o seu estudo dedicado à relação metáfora-símbolo parece apontar (1976, p. 45-69). Este radical não significa que descuremos os planos semiológico e semântico da metáfora, mas que, apenas e tão-somente, pretendemos encontrar as raízes da metáfora agrícola no plano do simbolismo vegetal com os seus ritos de renovação. Por outras palavras, defendemos que o uso da metáfora quer nos textos, quer nas práticas discursivas dos educadores e pedagogos não se deveria limitar tão-somente a uma abordagem de tipo semântico que faz da "similitudo" (HAMELINE, 1986, p. 124-127, 129-139; CHARBONNEL, 1999, p. 33) a sua pedra angular, senão mesmo do mero "comparar para fazer agir" (CHABONNEL, 1999, p. 35, 53-59; mas, antes pelo contrário, pode servir, como nos ensinou Paul Ricoeur (1976, p. 45-69), como uma espécie de farol para nos conduzir em direção a um substrato mais fundo, mais abaixo, mais radical que é domínio umbroso e multívoco do símbolo (aquilo que Paul Ricoeur identificou com o "O Momento não semântico de um Símbolo”, 1976, p. 57-63) e, muito particularmente, do simbolismo vegetal bem estudado, por exemplo, por Mircea Eliade (1994, p. 335-41; ARAÚJO, 2004, p. 177-191).

$\mathrm{O}$ poder metafórico, à semelhança de um riacho, não só vai desaguar a um rio subterrâneo designado símbolo como é também dele sintoma. Daniel Hameline, quanto a nós, esqueceu que há mais no símbolo do que na metáfora porque os símbolos pelo seu excesso de significação enraizados numa semântica profunda, a onírica, a poética e a cósmica " mergulham as suas raízes nas constelações duradoiras da vida do sentimento e do universo, e porque têm uma tão incrível estabilidade, levam-nos a pensar que um símbolo nunca morre, apenas se transforma" (RICOEUR, 1976, p. 64, 53, 1988, p. 167-186).

Do exposto compreende-se que a nossa atitude hermenêutica não se limite nem se conforme aos regimes semântico expressivo, cognitivo e praxeo-prescritivo dos enunciados metafóricos, estudados por Nanine Charbonnel na análise dos textos educacionais (1991, p. 128-164), por mais que eles se revelem úteis e pertinentes heuristicamente, mas procura ir mais longe na medida que para nós a metáfora funciona como uma espécie de rampa de lançamento para o mundo do simbolismo vegetal com

${ }^{31}$ Ver o nosso ponto 1.2. Da metáfora à metáfora em educação. 
as implicações míticas que dele decorrem (ARAÚJO, 2004, p. 169-194). Por outras palavras, pretendemos deixar bem claro que, na linha de Paul Ricoeur, se há mais na metáfora do que no símbolo, também há mais para lá da dimensão semântica da metáfora e este “mais” (RICOEUR, 1976, p. 69) ${ }^{32}$ identifica-se com o simbolismo vegetal que tem no símbolo da árvore uma dos seus melhores exemplos.

Por sua vez, este símbolo da árvore articula-se em torno da ideia de Cosmos vivo em contínua regeneração: "a árvore-imagem do cosmos; [...] a árvore-símbolo da vida, da fecundidade inesgotável, da realidade absoluta; [...] a árvore símbolo da ressurreição da vegetação da Primavera e da 'regeneração' do ano" (ELIADE, 1994, p. 337; CHEVALIER; GHEERBRANT, 1994, p. 89; BIERDERMANN, 1996, p. 42-46). Se o símbolo vegetal carece da metáfora agrícola para melhor se dar a ver, pois "Há mais na metáfora do que no símbolo, no sentido de que ela traz à linguagem a semântica implícita do símbolo" (Ricoeur, 1976: 69) ${ }^{33}$, também é verdade que a metáfora agrícola só se torna "viva" 34 quando ela absorve e reflete a "aura" do simbolismo vegetal na medida em que "O símbolo está ligado de um modo não presente na metáfora. Os símbolos têm raízes. Os símbolos mergulham na experiência umbrosa do poder" (1976, p. 69). Deste modo, defendemos que a metáfora agrícola bem pode constituir uma porta aberta para o simbolismo vegetal desde que ela seja "viva" no sentido que Paul Ricoeur lhe atribui, ou seja, quando essa metáfora produz uma inovação semântica inesperada ou inabitual $(1976 \text {, p. } 46-53)^{35}$, como pode igualmente ser prometedora do ponto de vista do simbolismo vegetal: "Através da vegetação, é a vida inteira, é a natureza que se regenera por múltiplos ritmos, que é 'honrada', promovida, solicitada. As forças vegetativas são uma epifania da vida cósmica" (ELIADE, 1994, p. 404). Neste contexto, aceitando a tese de Paul Ricoeur em que há uma relação osmótica entre metáfora

32 Paul Ricoeur escreve: "There is more in the metaphor than in the symbol in the sense that it brings to language the implicit semantics of the symbol what remains confused in the symbol. [...] But there is more in the symbol than in the metaphor. Metaphor is just the linguistic procedure - that bizarre form of predication - within which the symbolic power is deposited. [...] Metaphors are just the linguistic surface of symbols, and they owe their power to relate the semantic surface to the presemantic surface in the depths of human experience to the two-dimensional structure of the symbol" (1976, p. 69).

33 Hans Blumenberg numa mesma linha escreve: "De imediato, as metáforas podem ser restos, rudimentos no caminho do mito ao $\log 0$ " (2003, p. 44). Sobre a teoria da "metaphorologie" do autor e seus desenvolvimentos, consulte-se, por exemplo, Anselm Haverkamp \& Dirk Mende (Herausgeg. von). Metaphorologie: Zur Praxis von Theorie, 2009.

${ }^{34}$ Pensamos na obra de Paul Ricoeur intitulada The Rule of Metaphor (1994), enquanto Hans Blumenberg prefere usar o conceito de "metáfora absoluta" identificada com o mito (2003, p. 165-170), e Gaston Bachelard utiliza de "metáfora axiomática" para designar um tipo de metáfora de excelência e absoluta, que funciona, pelo menos assim nos parece, como um dos mais fortes reagentes da imaginação a par dos quatro elementos (terra, água, fogo e ar) caracterizados como "hormonas da imaginação" (2004, p. 19). 
(superfície linguística o símbolo) e símbolo (um fenómeno bidimensional em que a face semântica se refere à não semântica) (1976, p. 63-69), não nos parece hermenêuticamente prudente encararmos as metáforas hortícolas presentes na obra dos pedagogos e educadores da Educação Nova desligadas do simbolismo vegetal.

Aquilo que pretendemos dizer é que as metáforas hortícolas presentes nas suas obras não devem, na nossa perspetiva, ser encaradas como meras metáforas fechadas ao simbolismo vegetal na medida em que "a vegetação encarna (ou significa, ou participa em) a realidade que se faz vida, que cria sem se exaurir, que se regenera manifestandose em formas sem número, sem nunca se esgotar" (ELIADE, 1994, p. 403; ARAÚJO, 2004, p. 177-191). São certos símbolos de renovação, cujas raízes estão mergulhadas no magma da vida vegetal e por que não, como diria Paul Ricoeur, "nas constelações duradoiras da vida do sentimento e do universo" (1976, p. 64), que doam à metáfora hortícola os seus contornos semânticos e hermenêuticos específicos que apelam, como é conhecido, para uma teoria da metáfora purificada pelo logos que, ao ultrapassar os níveis semiótico e semântico da metáfora, se abre ao símbolo alimentado e regenerado pelo "Discurso na Vida" (RICOEUR, 1976, p. 59) e mesmo do mythos.

\section{Para uma conclusão: por que é importante a metáfora agrícola em educação?}

Torna-se útil, nesta última parte, refletirmos sobre os ensinamentos da metáfora em educação. Se, por um lado, "Não é de todo indiferente que o aluno seja comparado a um recipiente que se enche ou a uma planta que cresce"36 (HAMELINE, 1981, p. 121), por outro lado a metáfora, seja ela agrícola, da modelagem, da escultura, orgânica, da navegação, da viagem, etc., tende muitas vezes a olhar-nos, e quantas vezes nos surpreende, quando tratamos da educação nos seus mais variados suportes: textos, discursos, filmes, documentários, entrevistas e práticas pedagógicas.

A metáfora agrícola, aquela que mais nos ocupou ao longo do nosso estudo, muitas vezes se aproxima da metáfora viva que é aquela da invenção, da inovação semântica, da impertinência criativa, enfim aquela que produz uma nova informação por que "uma metáfora diz-nos algo de novo acerca da realidade" (RICOEUR, 1976, p. 53).

${ }^{36}$ Nunca é demais sublinhar que a metáfora do recipiente, ao fazer do aluno um recetáculo e submisso e do professor um despejador, consagra a ideia da Escola Tradicional da "cabeça bem cheia" (Montaigne) (a ideia da transmissão), enquanto a metáfora do crescimento, ao fazer do aluno um crítico do autoritarismo pedagógico e participativo na sua aprendizagem e do professor um jardineiro atento ao crescimento e interesses do aluno, consagra a ideia da Educação Nova da "cabeça bem-feita" (Montaigne) (a ideia da participação e dos "centros de interesse" (Decroly): "'On ne transmets pas, on ne peut transmettre une pensée comme on déverse un liquide d'un vase plein à un vase vide' » (HAMELINE, 1981, p. 124). 
Como vimos, a metáfora agrícola, na sua qualidade de "metáfora insistente"37 (1976, p. 68), aproxima-se da profundidade simbólica da existência e dos seus significados (WUNENBURGER, 2002, p. 43-65) e não se restringe simplesmente, como parece, em última instância, defender Daniel Hameline, ao "triunfo da similitude" (1986, p. 135138) por mais que esta seja pertinente, e certamente o é, no caso do uso da metáfora em educação:

Aceita-se que um aluno não é nem uma planta, nem um frasco, nem uma plasticina, nem um explorador, nem um arquiteto, nem um pássaro-raptor, nem um carro de corrida, nem um guaxinim. Mas compará-lo a uma planta, a um frasco, a uma plasticina, etc., e mesmo a um guaxinim permite dizer qualquer coisa que se pode controlar e que não é uma simples brincadeira nem um mero efeito de estilo (HAMELINE, 1986, p. 139).

Não é todo indiferente que o aluno seja comparado a um recipiente que se enche ou a uma planta que cresce. [...] todo o dito sobre a educação situa-nos, ainda por muito tempo, nas margens incertas da Retórica, lá onde reina a metáfora, na ambiguidade das suas compulsões repetitivas e das suas impertinencias criativas (HAMELINE, 1981, p. 121 e 131).

Defendemos, como o fez antes Paul Ricoeur (1965, p. 13-63; WUNENBURGER, 1997, p. 76-85), que a metáfora viva, como é muitas vezes o caso da metáfora agrícola ou do crescimento em educação, não se pode fechar ao olhar dos símbolos que nos envolvem e que nos habitam, veja-se o exemplo do simbolismo vegetal nas suas dimensões cósmica, poética e onírica. A razão disso é que as raízes dos símbolos mergulham simultaneamente na experiência umbrosa do poder cósmico, poético e onírico, assim como nas profundidades simbólicas da nossa existência e da vida.

Um transbordamento que nos conduz naturalmente ao "Momento não Semântico de um Símbolo" (RICOEUR, 1976, p. 57-63) ${ }^{38}$ interpelando-nos no mais íntimo de nós mesmos, à semelhança das raízes que murmuram amorosamente com Gaia (a Mãe Terra), e do seu tronco e ramos que comunicam com a deusa Eos (deusa do amanhecer e

${ }^{37}$ Uma metáfora insistente, que é mesmo fundacional e pregnante simbolicamente, valoriza o sentido figurado em detrimento do sentido próprio, o sentido equívoco em detrimento do sentido unívoco e, finalmente, valoriza a conotação, que despoleta associações subjetivas, em detrimento da denotação que privilegia o referente objetivo e mais informativo.

38 Ainda que a metáfora diga, como o referiu Daniel Hameline, alguma coisa que se pode controlar nos textos e discursos sobre a educação, tal não significa que o seu sentido simbólico, pela sua denotação multívoca, não escape à simples retórica do significado para postular todo um trabalho de interpretação sobre o sentido escondido que transborda em muito a configuração semântica da metáfora (LEVIN, 1977; COHEN, 1993, p. 58-70). 
do entardecer, do brilho do sol e das matizes do céu ${ }^{39}$. Por isso, Paul Ricœur, pelo seu lado, pode pertinentemente afirmar que "A metáfora ocorre no universo já purificado do logos, ao passo que o símbolo hesita na linha divisória entre o bios e o logos. Dá testemunho da radicação primordial do Discurso na Vida. Nasce onde a força e a forma coincidem"

(1976, p.71), bem como Jean Brun pôde justamente escrever:

\begin{abstract}
Os símbolos verdadeiros não são signos de reconhecimento, não são mensageiros da presença, mas antes mensageiros da Ausência e da Distância. É por isso que são eles que vêm a nós e não o contrário como em direção a um objetivo que teríamos mais ou menos conscientemente colocado diante de nós. Os símbolos são as testemunhas daquilo que nós não somos; se nos dispusermos a escutálos, é porque eles vêm irrigar as nossas palavras de uma água que nós seríamos incapazes de fazer jorrar a fonte. Como o dizia Beaudelaire, os símbolos observam-nos; quando nós sentimos o seu olhar, temos a impressão de uma presença que poderia ter a sua origem num algures conhecido. É por isso que os símbolos anunciam mais do que aquilo que enunciam (1985, p. 81-82).
\end{abstract}

Assim sendo, também as metáforas encontradas nos textos pedagógicoeducacionais da modernidade educativa, especialmente a metáfora agrícola que se interessa pelo crescimento e pelo desenvolvimento, à semelhança dos símbolos, anunciam mais do que aquilo que elas enunciam. Tal foi o caso, no nosso estudo, da metáfora agrícola que, a seu modo, anunciou o caminho do simbolismo vegetal com tudo aquilo que este simbolismo significa nos planos cósmico, poético, onírico e existencial. Deste modo, importa destacar que o valor da metáfora agrícola educacional ultrapassa os planos retórico e pedagógico para se situar num mais além, a saber: nos planos simbólico e educacional.

\title{
Referências
}

ACKER, V. The French Educator. Célestin Freinet (1896-1966): An Inquiry into how his ideas shaped education. Lanham, Maryland: Lexington Book, 2007.

39 Veja-se que uma imagem torna-se simbólica a partir do momento em que através do seu conteúdo sensível ela suscita, ou sugere, uma cadeia de imagens guiadas por um significado virtual (vida, morte, paz, felicidade, etc). Se olharmos o exemplo da árvore, além de vermos a espécie vegetal real que ela representa (saber científico), ela pode igualmente despertar na consciência o seguinte: "un jardin d'agrément ou la coupe du bois pour chauffer, mais peut orienter, ensuite, vers la pensée de la vie et même d'une vie dotée d'une longévité impressionnante, et finalement vers l'idée d'une éternité par-delà la mort" (WUNENBURGER, 2011, p. 16-17). 
ARAÚJO, A. F. Educação e Imaginário: Da Criança Mítica às Imagens da Infância. Maia: Instituto Superior da Maia, 2004.

AUDET, M. A Pedagogia Freinet. In C. GAUTHIER \& M. TARDIF (Eds.). A pedagogia: teorias e práticas da Antiguidade aos nossos dias. Trad. de Lucy Magalhães. Petrópolis: Editora Vozes, 2010, p. 253-269.

BLACK, M. Models and metaphors: Studies in language and philosophy. Ithaca, New York: Cornell University Press, 1962.

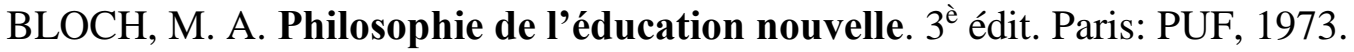

BLUMENBERG, H. Paradigmas para una Metaforologia. Trad de Jorge Pérez de Tudela Velasco. Madrid: Edit. Trotta, 2003.

BOUMARD, P. Célestin Freinet. Paris: PUF, 1996.

BRUN, J. L'homme et le langage. Paris: PUF, 1985.

CHARBONNEL, N. Apport des herméneutiques du texte à l'étude du discours sur l'éducation: la place de la métaphore. In: Sciences Anthropo-Sociales: Sciences de l'Éducation. Actes - Colloque National (Paris - INA - 16/18 Septembre). Paris, Association des Enseignants et Chercheurs en Sciences de l'Éducation, 1983. p. 156159.

CHARBOnNEL, N. Les Aventures de la Métaphore. In: La Tâche aveugle (vol. I). Strasbourg: Presses Universitaires de Strasbourg, 1991.

CHARBONNEL, N. L'important c'est d'être propre. In: La Tâche aveugle (vol. II). Strasbourg : Presses Universitaires de Strasbourg, 1991a.

CHARBOnNEL, N. Philosophie du Modèle. In: La Tâche aveugle (vol. III). Strasbourg: Presses Universitaires de Strasbourg, 1993.

CHARBONNEL, N. Freinet ou une Pensée de la Similitude, en Clanché P., Debarbieux É., Testanière J. (sous la dir. de) La Pédagogie Freinet: mises à Jour et Perspectives. Bordeaux, Presses Universitaires de Bordeaux, 1994. p. 51-59.

CHARBONNEL, N. Métaphore et Philosophie Moderne. In N. Charbonnel \& G. Kleiber (Ed.) La métaphore entre philosophie et rhétorique. Paris : PUF, 1999. p. $32-61$.

CHARBONNEL, N. Freinet ou une Pensée de la Similitude. In: CLANCHE, P.; DEBARBIEUX, E.; TESTANIERE, J (Eds.) La Pédagogie Freinet: mises à Jour et Perspectives. Bordeaux: Presses Universitaires de Bordeaux, 1994, p. 51-59.

CLAPARÈDE, Éd. Psychologie de l'Enfant et Pédagogie Expérimentale. I. Le développement mental. Édit posthume. Neuchâtel-Paris, Delachaux \& Niestlé, 1946.

ClAnChe, P.; DEBARBIEUX, E.; TESTANIERE, J (Eds.) La Pédagogie Freinet: mises à Jour et Perspectives. Bordeaux: Presses Universitaires de Bordeaux, 1994, p. 51-59. 
COHEN, L. J. The semantics of metaphor. In. A. ORTONY (ed.). Metaphor and Thought. $2^{\text {nd }}$ edition. Cambridge: Cambridge University Press, 1993. p. 58-70.

ELIADE, M. Tratado de História das Religiões. Trad de Natália Nunes e Fernando Tomaz. $2^{a}$ ed. Porto: Asa, 1994.

FREINET, C. Guvres Pédagogiques. Tomes I et II. Édition établie par Madeleine Freinet. Paris: Éditions du Seuil, 1994.

FREIRE, P. Pedagogia do Oprimido. 36ª ed.. Rio de Janeiro: Paz e Terra, 2003.

GENNARI, M. Bildung. In V. Melchiorre (Ed.) Enciclopedia filosofica. Vol. II. Milano: Bompiani, 2006. p. 1262-1264.

GIBBS Jr., R. W. (ed.). The Cambridge handbook of metaphor and thought. Cambridge: Cambridge University Press, 2008.

HAMELINE, D. Place et fonction de la métaphore dans la pensée sur l'éducation ou éloge de la rhétorique. Éducation et Recherche, v. 3, p. 121-132, 1981.

HAMELINE D. L'éducation, ses images et son propos. Paris : Éditions ESF, 1986.

HAMELINE D. Courants et contre-courants dans la pédagogie contemporaine. Paris : ESF éditeur, 2000.

HAMELINE, D.; CHARBONNEL, N. L'éducation et ses métaphores, recueil thématique. Genève: Centrale des polycopiés de l'Université de Genève, 1982-1983.

HAMELINE, D.; HELMCHEN, J.; OELKERS, J. L'Éducation Nouvelle et les Enjeux de son Histoire. Bern: Peter Lang, 1995.

HAVERKAMP, A.; MENDE, D. (Herausgeg. von). Metaphorologie: Zur Praxis von Theorie. Frankfurt : Suhrkamp Verlag, 2009.

HINTIKKA, J. (Ed.). Aspects of Metaphor. Dordrecht/Boston/London: Kluwer Academic Publishing, 1994.

JOHNSON, M. Philosophical Perspectives on Metaphor. Minneapolis: University of Minnesota Press, 1981.

LAKOFF, G. \& JOHNSON, M. Les métaphores dans la vie quotidienne. Trad. par Michel de Fornel. Paris : Éditions de Minuit, 1986.

LEGRAND, L. Célestin Freinet (1896-1966). Prospects: the quarterley review of comparative education. v. XXIII, n. 1/2, p. 403-418, 1993.

LEVIN, S. R. The Semantics of Metaphor. Baltimore: John Hopkins Press, 1977.

MAURY, L. Freinet et la pédagogie. Paris: PUF, 1988.

MÉDICI, A. L’Éducation Nouvelle. 14̀̀ édit. Paris: PUF, 1995. 
MONTAIGNE, M. Da educação das crianças. In: MONTAIGNE, M. A Educação das Crianças. Trad. de Rosemary Costhek Abílio. S. Paulo: Martins Fontes, 2005. p. 31122.

MONTESSORI, M. Educazione e pace. Roma: Opera Nazionale Montessori, 2004.

MORIN, E. La Tête Bien Faite. Repenser la reforme: Réformer la pensée. Paris: Éditions du Seuil, 1999.

NÓVOA, A. Uma Educação que se diz "Nova". In A. CANDEIAS; A. NÓVOA \& M. H. FIGUEIRA. (org.) Sobre a Educação Nova: Cartas de Adolfo Lima e Álvaro Viana de Lemos (1923-1941). Lisboa: Educa, 1995. p. 25-41.

NÓVOA, A. Regards Nouveaux sur l'Éducation Nouvelle. In N. CHARBONNEL (Textes réunis par). Le Don de la Parole. Mélanges offerts à Daniel Hameline pour son soixante-cinquième anniversaire. Bern: Peter Lang, 1997, p. 71-96.

NÓVOA, A. Evidentemente: Histórias da Educação. 2a ed. Porto: Asa, 2005.

ORTONY, A. (ed.). Metaphor and Thought. $2^{\text {nd }}$ edition. Cambridge: Cambridge University Press, 1993.

PAIN, Jacques. FREINET Célestin - (1896-1966). Encyclopaedia Universalis [en ligne] consultado em 9 dezembro $2015 . \quad$ URL: http://www.universalis.fr/encyclopedie/celestin-freinet/.

PERELMAN, Ch. L'empire rhétorique: Rhétorique et argumentation (2 è éd.) Paris, J. Vrin, 1988.

PERELMAN, Ch. Rhétoriques. Bruxelles, Éditions de l’Université de Bruxelles, 1989.

PERELMAN, Ch.; OLBRECHTS-TYTEKA, L. Traité de L'Argumentation: La Nouvelle Rhétorique. Bruxelles, Éditions de l’Université de Bruxelles, 1992.

PEYRONIE, H. Célestin Freinet. In. J. HOUSSAYE (edit.). Quinze Pédagogues. Leur influence aujourd'hui. Paris: Armand Colin, 1994. p. 212-226.

PEYRONIE, H. Célestin Freinet: pédagogie et émancipation. Paris : Hachette, 1999.

PIATON, G. (1974). La Pensée Pédagogique de Célestin Freinet. Toulouse: Privat, 1974.

REBOUL, O. Le langage de l'éducation. Paris : PUF, 1984.

REBOUL, O. Introduction à la rhétorique. $2^{\mathrm{e}}$ éd. Paris : PUF, 1994.

REBOUL, O. Qu'est-ce qu'apprendre? 9e éd. Paris : PUF, 2001.

RICOEUR, P. De l'interprétation: Essai sur Freud. Paris : Éditions du Seuil, 1965.

RICOEUR, P. Interpretation Theory: Discourse and the Surplus of Meaning. For Worth, Texas: The Texas Christian University Press, 1976. 
RICCEUR, P. Philosophie de la volonté. II - Finitude et culpabilité. Paris: Aubier, 1988.

RICOEUR, P. The Rule of Metaphor: Multi-disciplinary of the creation of meaning in language. Translated by Rober Czerny et all. London: Routledge, 1994.

SCHEFFLER, I. Le langage de l'éducation. Trad. de Michel Le Du. Paris: Klincksieck, 2003.

SIVELL, J. (ed.) Freinet Pedagogy: theory and Practice. Lewiston NY: Edwin Mellen Press, 1994.

SNYDERS, G. Pédagogie progressiste: education traditionnelle et éducation nouvelle. Paris: PUF, 1975.

VASCONCELOS, A. F. de. Une école nouvelle en Belgique. Neuchâtel: Delachaux \& Niestlé, 1915.

WUNENBURGER, J.-J. Philosophie des images. Pars : PUF, 1997.

WUNENBURGER, J.-J. La vie des images. Grenoble: PUG, 2002.

\section{Como referenciar este artigo}

ARAÚJO, Alberto Filipe. Poderá a modernidade educativa dizer-se sem Célestin Freinet? O uso da metáfora agrícola para se pensar em educação. Revista IberoAmericana de Estudos em Educação, Araraquara, v. 12, n. esp. 1, p.564-590, 2017. Disponível em: <http://dx.doi.org/10.21723/riaee.v12.n.esp.1.2017.9663>. E-ISSN: 1982-5587.

Submetido em: 07/04/2017

Aprovação final em: 10/04/2017 